Narrative counselling for adolescents at risk of exclusion from school

Shaalan Farouk and Simon Edwards

Psychology Department, New York University Abu Dhabi, Abu Dhabi, United Arab Emirates

School of Education and Sociology, University of Portsmouth, Portsmouth, England

Dr.Shaalan Farouk New York University Campus, Saadiyat Island, Abu Dhabi, PO Box

129188. Email: sf144@nyu.edu 


\section{Narrative counselling for adolescents at risk of exclusion from school}

A new form of narrative counselling for adolescents at risk of exclusion was piloted in three schools with eleven students between the ages of 13-14 years over a 6-7week period. The intervention took into consideration that compared to adults, adolescents are more susceptible to being influenced by their immediate surroundings of home and school. A measure of progress on a student engagement scale showed an improvement in educational engagement, particularly in students' behavioural engagement in class. The process of narrative counselling adolescents at school is described and the issues addressed in the narrative counselling sessions are discussed. Finally, the inclusive ethos of the secondary schools that the counsellors worked in are considered, as they facilitated or hindered the counselling intervention

Key Words: narrative approach, counselling in school, adolescents, social constructionism 


\section{Introduction}

In education, early adolescence is a period of change from the relatively nurturing and tolerant environment of primary school to the more impersonal and self-reliant world of secondary school education (Farouk, 2017; Symonds, 2015). Most adolescents manage this transition well and they flourish in the more autonomous context of secondary schools. Yet, there are also an increasing number of adolescents in England who become disengaged from education and begin to display persistent socio-emotional difficulties and challenging behaviour. Recent data provided by the Institute for Public Policy Research (Gill, QuilterPinner, \& Swift, 2017) indicated that between 2012 and 2016 there was an increase by $40 \%$ in the recorded number of permanent exclusions from school, from 4100 to 6700 excluded pupils. According to the IPPR and a recent government report this amounts to between 3540 students being excluded a day (Department for Education, 2019). Of growing concern is that these figures do not include unofficial exclusion from school, that do not require the school to follow exclusion procedures, referred to as "functional exclusions" (Gill et al., 2017). The data presented by the IPPR indicate that the total number of effectual exclusions from school are in fact five times higher than official records would suggest and therefore stand at about 33,500 per annum. In addition, data from the department of education shows that over $60 \%$ of all permanent exclusions take place between the age of 13 and 14 years (Department for Education, 2010, 2015).

Within this context, we conducted narrative counselling in three schools in England to help early adolescents who were considered to be at risk of exclusion because of displaying challenging behaviour and disrupting other students' education. Narrative counselling is grounded in narrative psychology, which assumes that individuals' sense of who they are and what they may become depend on their autobiographical memories created within their sociocultural world (for instance, Bruner, 1987; Fivush \& Merrill, 2016; McAdams, 2003). This 
narrative interpretation of identity, foregrounds how individuals' perceptions of themselves are constructed within their socio-cultural word by dialogical interactions with significant others and, when reflecting on past events, by themselves. The purpose of narrative counselling is to make these internalized dialogues, informed by beliefs and assumptions developed over time, explicit so that they can be reflected on and reframed (Madigan, 2019; Payne, 2006).

The aims of this paper are to describe how narrative counselling can be used to support adolescents at school, identify themes in student narratives that were the focus of the intervention, and to highlight the challenges and limitations of the intervention within a performance focused institutional context.

\section{Narrative Counselling Adolescents at School}

According to (Erikson, 1959) and McAdams(2003), the development of an identity for an emerging adult world begins in adolescence, when young people are afforded greater independence and become increasingly aware of their social world and the roles that they are expected to play within it. In adolescence, and early adolescence in particular, most individuals are only at the beginning of creating a life story that provides them with a coherent sense of who they are and what they may become (Habermas \& de Silveira, 2008) Findings from cross-sectional and longitudinal research on adolescent life stories have demonstrated that personal memories are still fragmented and that the ability to construct a coherent autobiography, and thus acquire a stable identity, does not manifest itself until late adolescence and emerging adulthood (Bohn \& Berntsen, 2008; Grysman \& Hudson, 2010; Habermas \& de Silveira, 2008; Köber, Schmiedek, \& Habermas, 2015). This manifestation of a less stable and more open identity in adolescence, has also been supported by social psychological research on how adolescents are much more susceptive to social influences 
than adults from their peer groups and friends with whom they spend most of their time (Collibee, Le Tard, \& Wargo Aikins, 2016; Cullingford \& Morrison, 1997; Hartup \& Stevens, 1999). Moreover, research has highlighted how early emotional autonomy from parents, without yet having become self-sufficient individuals, increases the likelihood of coming under the influence of friends and being susceptible to peer group pressure (Chan \& Chan, 2013; Chester, Jones, Zalot, \& Sterrett, 2007; Helsen, Vollebergh, \& Meeus, 2000; Steinberg \& Silverberg, 1986).

The limited extent to which adolescents have created an established and coherent life story has important implications for narrative counselling and the approach adopted here. While most forms of narrative counselling with adults is focussed on reframing an established autobiography and narrative identity (Milner \& O'byrne, 2002; Payne, 2006; Ungar, 2001), the emphasis in counselling adolescents, is to validate their personal memories and co-construct a life story, usually for the first time, that provides the young persons with a sense of themselves in the past, in the present and in the future. This creation of a storied past and exploration of future possibilities is followed by a detailed examination of recent events and the social influences and personal convictions that shaped their behaviour at the time. In the exploration of recent events, the perceptions of significant others (such as their parents, teachers and peers) and the constructive or unhelpful influences they may have had on them, are foregrounded and re-examined in detail. The examination of current events is accompanied by making comparisons to how they related to others in the past and what they would like things to be like in the future. For instance, one issue raised may be adolescents' antagonistic relationships with teachers and the discussion may therefore focus on how these relationships were different at primary school and their first year at secondary school. By exploring such differences students can identify differences in their own changing identity as students, which to a substantial extent were shaped by their relationships with significant 
others at different times. These notable differences then provide the leverage to propose alternative ways of interpreting current circumstances, and the next step is to develop actions that they, with the help of others, can engage in. Based on the students' new understandings they are then invited to try out alternative ways of interacting with teachers, that are then reviewed and revised on a weekly basis.

Adolescence is a period of transition from child to adulthood and while independence is increasingly bestowed on adolescents as they grow older their freedom and autonomy is still kept within clear limits, particularly at school. To address this lack of actual independence, the counsellor from the outset, establishes a working relationship with their parents and relevant members of staff as they have considerable authority over any changes that can be made. Moreover, their awareness and supportive attitude towards any alternative actions that the adolescent takes are extremely important for the success of the intervention. In consequence, the actions agreed in the sessions do not remain personal or confidential but are, with the students' consent, shared with parents, and relevant teachers.

\section{Narrative Counselling Process}

Narrative counselling was provided as part of a research project, entitled Narrative Solutions, to examine the potential benefits of providing such an intervention for adolescents at risk of exclusion from mainstream schools. The intervention was conducted in three schools by an educational psychologist and former youth worker employed as university lecturers in England. The diverse training and professional experience of the two counsellors helped to create a form of counselling adolescents that was not only informed by narrative psychology, but also took into consideration the very different and separated social worlds that participants inhabited at school and in their communities at home. In preparation for the provision of narrative counselling agreements were reached with each school as to the length 
and format of the intervention, the engagement of a senior member of staff to make arrangements for the weekly visits of the narrative counsellor, and the need to liaise with relevant teachers when required to do so.

Potential participants were identified by the school because of their challenging behaviour and the potential risk of permanent exclusion from school if their conduct did not improve. For the intervention we obtained ethical approval and followed the ethical guidelines of both universities. The school, participants and their parents were informed of the nature and the purpose of the intervention and we obtained consent from all three before engaging in the intervention. Participants and their parents were also informed that this was offered to the school as an early intervention for students whose behaviour had become an area of substantial concern. In addition, participants and their parents were made aware that participation was voluntary, that they could withdraw at any time, and that no other alternative intervention was available at the school. Following university ethical guidelines participants were also made aware that their identity would remain confidential and would not be disclosed in publications on the research project.

The counselling sessions took place in multicultural school A located in London that catered for about 700 boys, and school B and C, located in West Sussex and Hampshire, that catered for 1150 and 1000 mostly white British students. All three institutions were state schools that functioned within in a competitive education system in which success was measured according to national examination results and regular government inspections focussed on academic performance.

Before the narrative counselling with students begun a meeting was arranged with parents and the student at home not only to introduce and explain the intervention to them, but also to embed the intervention within the participants' lives outside of school and to seek 
the parentls' support. The home visits were followed by the first session in which the counsellor conducted autobiographical interviews with participants at school. These interviews begun by asking each participant to separate their lives into chapters, that represented significant periods in their lives, and to entitle these chapters (e.g. before movinghouse, year 2, year 3, new teacher). The students were then asked to talk about each chapter and recollect any typical or specific events from that period in their lives. These interviews were recorded and transcribed, and a short autobiography was created by the counsellor, which was presented to students in the second session so that they could add their comments and corrections. The purpose of these co-authored autobiographies was to provide them with a coherent backstory that demonstrated how their relationships with teachers and engagement with school had changed over time. In most cases their relationship with teachers was positive at primary school but had become antagonistic at secondary, while at the same time they still relied on the personal support of teachers, to help them engage in and stay focused on their work in class. The second session was then followed by four narrative counselling sessions and one final meeting with the student and his/her parents. In these sessions participants were encouraged to talk about their life at school and to reflect on what had been problematic and what had been going well since the previous weekly session. For both their positive and negative experiences the influence of significant others were foregrounded and discussed. As appropriate, further comparisons were also made to similar events in the past (as described in their autobiographical recollections) to highlight the extent to which patterns of behaviour re-occur, and to identify actions that the participant may take to break such patterns of behaviour, sometimes with the support of parents and/or their teachers. The format of these counselling session were also kept the same so that on each occasion the counsellor helped the student, with the benefit of hindsight, to re-examine his/her internalized narrative of recent events and to consider alternative explanations and courses of actions that 
could be taken, when a similar set of circumstances present themselves. The two counsellors who conducted the counselling sessions kept in regular contact with one another not only to discuss the progress of the intervention but also ensure that the format and method of the counselling sessions remained consistent. For an overview of the intervention see table 1.

Table 1: Overview of the Intervention Process

\begin{tabular}{|c|c|}
\hline Intervention & Summary Description \\
\hline $\begin{array}{l}\text { Meeting with } \\
\text { parent/s and } \\
\text { student at home }\end{array}$ & $\begin{array}{l}\text { The purpose of the meeting is to explain the intervention to the family } \\
\text { and the student and to ask for their written consent, listen to the } \\
\text { parent/s' and the adolescent's views about his/her time at school, } \\
\text { obtain the story of parent/s' own experience of school and gain their } \\
\text { support. The aim of the home visits was to reset the students' personal } \\
\text { narratives about their education, and its importance, within the context } \\
\text { of their families and their community }\end{array}$ \\
\hline $\begin{array}{l}\text { Session 1: } \\
\text { Autobiographical } \\
\text { Interview at } \\
\text { school }\end{array}$ & $\begin{array}{l}\text { The students create an autobiographical narrative of their experience } \\
\text { of school, with the support of the counsellor. The interviews are } \\
\text { recorded and a short autobiography is produced by the counsellor for } \\
\text { the following sessions. }\end{array}$ \\
\hline $\begin{array}{l}\text { Session 2: } \\
\text { Narrative } \\
\text { Solution Focused } \\
\text { Session }\end{array}$ & $\begin{array}{l}\text { At the start of the session the short autobiography is presented to the } \\
\text { student and s/he is given the opportunity to add details and make } \\
\text { changes to the story. Any recurring themes in the autobiography are } \\
\text { highlighted and discussed. This is then followed by discussing with } \\
\text { the student which of these recurring themes s/he wishes to change the } \\
\text { most. Specific events that are representative of this theme are then } \\
\text { examined in detail highlighting key figures that may have had an } \\
\text { influence on them at the time. These events are then compared to other } \\
\text { similar situations (in the past and the present) and possible reasons for } \\
\text { differences in outcome are highlighted and discussed. At the end of } \\
\text { the session actions that the student may wish to take are discussed and } \\
\text { eventually agreed upon. The proposed actions are shared with parents } \\
\text { and teachers, and if necessary their support in taking action is sought. }\end{array}$ \\
\hline $\begin{array}{l}\text { Session 3- } 6 \\
\text { Reflecting on } \\
\text { current events, } \\
\text { reviewing } \\
\text { progress and } \\
\text { improving or } \\
\text { changing the } \\
\text { intervention }\end{array}$ & $\begin{array}{l}\text { To talk about what has been happening since the previous session, the } \\
\text { week before. The focus is on helping the student reflect on what has } \\
\text { gone well and what has been problematic in the last few days. Issues } \\
\text { that arise are elaborated on and the influence of significant others, both } \\
\text { positive and negative, are discussed. If necessary further comparisons } \\
\text { are made to similar events in the past where they were successful to } \\
\text { identify further actions that may be taken by the student, and if } \\
\text { necessary parents and/or teachers. }\end{array}$ \\
\hline
\end{tabular}




\begin{tabular}{|ll|}
\hline & $\begin{array}{l}\text { Towards the end of the session the agreed upon actions are improved } \\
\text { on or changed depending on the progress that has been made. The } \\
\text { proposed actions are shared with parents and teachers. }\end{array}$ \\
\hline $\begin{array}{l}\text { Final Session: } \\
\text { Review of the } \\
\text { progress that has } \\
\text { been made and } \\
\text { bringing the } \\
\text { intervention to an } \\
\text { end }\end{array}$ & $\begin{array}{l}\text { In the final session, the autobiography created in session 1 is shared } \\
\text { and the student and counsellor review the progress that has been made. } \\
\text { Allustrate the progress that has been made. The aim is for the students } \\
\text { to come away with a progressive autobiographical narrative and a } \\
\text { sense of agency about themselves as learners. }\end{array}$ \\
\hline $\begin{array}{l}\text { Meeting with } \\
\text { Parents, teacher/s } \\
\text { and student at } \\
\text { school }\end{array}$ & $\begin{array}{l}\text { Meeting teacher/s, parents and the student to thank them for their } \\
\text { support and to discuss how the progress made can be maintained. }\end{array}$ \\
\hline
\end{tabular}

\section{Participants}

The intervention involved seeing a total of 11 students individually over a period of six to seven weeks per pupils between 2015 and 2017. Four male participants attended school A, three male and two female participants came from school B and 2 male participants came from school C. The participants were selected by each school because of their disruptive behaviour and risk of permanent exclusion from school. Sessions took place on a weekly basis and took between 30-45 minutes. So that parents and relevant teachers could also support the intervention contact was maintained with them by email, text messages and on occasion telephone conversations.

The names of the participants have been changed and only general information regarding their background is provided to maintain confidentiality. The participants from school A were David, George, Alex and Lenny. They were all born in England, and David's and George's parents came to London as refugees from Eastern Europe and the Middle East. According to their teachers they were easily distracted by other students, did not get on with their work in class. In addition, Alex found it very difficult to get along with certain teachers, 
and Lenny would get into fights with others students. The participants from school B and C were all British. The students from school B were Ben, Chelsea, Dean, Hayley and Sam. Their teachers described Sam, Hayley and Chelsea as coming from challenging home circumstances, which contributed to their difficulties at school. Both Sam and Hayley could be rude and dismissive of authority at school, and Hayley could also become easily upset and angry in class. Chelsea's relationship with teachers varied, and she became disruptive when she felt that she had been treated unfairly by her classmates and/or the teacher. Chelsea was also critical of teachers who were not able to control class.

Finally, the participants from school $\mathrm{C}$ were Oscar and Finley. According to his teachers Finley could be defiant in class, argue with the teachers and walk out of lessons. He also had a strong sense of what he considers to be right and wrong. Oscar was described as easily influenced by his peers and reluctant to follow instructions. Then when confronted by his teacher he would argue and then leave the classroom, if the teacher did not give in to his demands.

\section{Data Collection and Analysis}

The purpose of this intervention and qualitative research project is to describe and consider how narrative counselling may be applied to support adolescents at school. To this end, data was collected from a small number cases to provide a detailed description and analysis of the potential benefits and limitation of such an intervention. Alongside qualitative date that was analysed thematically, numerical data on student engagement with education was also collected to obtain an indication of the progress that they had made over the period of the intervention. Given the small number of participants, that do not constitute a representative of a wider population, the data obtained is only an indication of the progress that this kind of students can make. 
To collect numerical data on their educational engagement participants were asked to complete the student engagement scale developed by Conner and Pope (2013). This scale was chosen because of a positive correlation having been identified between levels of engagement in education and reduced conduct disorder and exclusion from school (Griffiths, Lilles, Furlong, \& Sidhwa, 2012). We selected the scale developed by Conner and Pope specifically as it contains separate measures for behavioural, cognitive and affective engagement, so that comparisons can be made between student engagement on these three dimensions. On the scale the behaviour dimension consists of questions about the completion of assignments, paying attention and the effort made both physically and mentally. The cognitive dimension consists of items regarding the perceived usefulness, and value of work in class, and the extent to which the work is considered meaningful. Finally, the affective engagement dimension contains items on the extent to which schoolwork is enjoyable, interesting and fun.

The scale was administered by the counsellor before and soon after the intervention was completed. The scale is designed to measure student engagement in learning at the level of the school. The students, however, experienced most difficulties in their learning and/or relating to their teacher in specific lessons, so that these became the focus of the counselling sessions. For the purpose of this study the questionnaire was therefore adapted to focus on their engagement in those subjects in which these students felt they wanted to improve their conduct and their engagement with learning the most.

The intervention also included a thematic analysis (Boyatzis, 1998; Braun \& Clarke, 2006) of the short autobiographies, to identify patterns in how participants have been relating to other students and teachers, and how they have been managing the relationship between home and school. This analysis of the autobiographies did not include an in-depth interrogation and interpretation of participants' personal recollections but instead focused on 
participants' description of events and the identification of social interaction patterns that seemed to repeat themselves in different contexts. The analysis therefore remained at the level of how situations were described in participants' short autobiographies. The purpose of identifying such themes was to provide the counsellor and the participant with patterns of social behaviour that they could then reflect on more deeply in the sessions.

While some of the themes identified within autobiography were only of relevance to that specific case there were also themes that applied to most participants and could therefore be placed under the same category or higher order themes. Towards the end of the interventions, we identified the two related higher order themes of struggling with the level of independence and self-sufficiency expected from them at secondary school, and the negative influence of their peers on their behaviour and ability to learn. Before examining these themes in some detail, the findings from the student engagement questionnaires are described and discussed.

\section{Findings}

\section{Student Engagement}

At the start and the end of the intervention students were asked to complete the Student Engagement Questionnaire (Conner \& Pope, 2013), and the results are displayed in table 2. The only students who did not complete the student engagement scale were Oscar and Finley from school $\mathrm{C}$, as the school did not take the second measure after the intervention was completed. The reason for this (as will be discussed in the following sections) was that school C changed its behaviour policy during the intervention which affected the students' progress and the relationship with the counsellor.

Participants reported having made substantial progress in their behavioural engagement, and less substantial progress in their cognitive and affective engagement. In 
fact, all the students marked an improvement in their behavioural engagement with an average increase of 2.2 points on the five point scale. On the self-report scale participants made less progress on the cognitive engagement and affective engagement scales, with an average increase of 1.1 points. One explanation for this limited increase is that the intervention did not involve altering the curriculum or pedagogy and it was therefore less likely to have had an impact on cognitive engagement (the perception of school work as valuable and meaningful) and affective engagement (on classroom activities being enjoyable and fun).

These findings, based on participants' self-evaluation, were supported by the weekly records school A and B kept on the behaviour of students in class. These records consisted of comments made by subject teachers, on a centralized recording system, regarding any problematic behaviour in class, before, during and immediately after the intervention. In schools A and B if there were three such comments, or a major incident, in a week then the pupil would be "put on report", which meant that his/her behaviour was being closely monitored in all of his lesson. All of the participants had been put on report and stayed on report the term before the intervention. During the intervention none of the participants were put on report, and there were only three and four behavioural incidents recorded in total in school A and in school B. 
Table 2: Levels of change in behavioural, cognitive and affective engagement before and after the intervention

\begin{tabular}{|l|l|l|l}
\hline 0 level increase & 1 point increase & 2 point increase & 3 point increase \\
\hline
\end{tabular}

\begin{tabular}{|c|c|c|c|c|c|}
\hline School & Participant & Subject & $\begin{array}{l}\text { Behavioural } \\
\text { Engagement }\end{array}$ & $\begin{array}{l}\text { Cognitive } \\
\text { Engagement }\end{array}$ & $\begin{array}{l}\text { Affective } \\
\text { Engagement }\end{array}$ \\
\hline \multirow{8}{*}{$\begin{array}{l}\frac{\Omega}{\rho} \\
\frac{\rho}{\delta} \\
\frac{\delta}{D}\end{array}$} & \multirow[t]{2}{*}{ David } & English & $2-5$ & $3-5$ & $3-4$ \\
\hline & & Maths & $2-4$ & $3-5$ & $3-4$ \\
\hline & \multirow[t]{2}{*}{ George } & Maths & $2-5$ & $3-4$ & $4-4$ \\
\hline & & Science & $2-5$ & $2-4$ & $4-4$ \\
\hline & \multirow[t]{2}{*}{ Alex } & Science & $3-5$ & $4-4$ & $3-4$ \\
\hline & & Art & $2-5$ & $4-4$ & $4-5$ \\
\hline & \multirow[t]{2}{*}{ Lenny } & English & $2-5$ & $4-4$ & $4-4$ \\
\hline & & Art & $2-4$ & $2-4$ & $5-5$ \\
\hline \multirow{10}{*}{$\begin{array}{l}\tilde{\Omega} \\
\tilde{\delta} \\
\stackrel{0}{0} \\
0\end{array}$} & \multirow[t]{2}{*}{ Ben } & English & $1-4$ & $4-5$ & $2-2$ \\
\hline & & Maths & $2-4$ & $4-4$ & $2-4$ \\
\hline & \multirow[t]{2}{*}{ Chelsea } & English & $3-4$ & $1-3$ & $2-3$ \\
\hline & & Maths & $1-4$ & $3-4$ & $3-5$ \\
\hline & \multirow[t]{2}{*}{$\overline{\text { Dean }}$} & English & $4-5$ & $3-5$ & $3-5$ \\
\hline & & Maths & $4-5$ & $3-4$ & $3-5$ \\
\hline & \multirow[t]{2}{*}{ Hayley } & English & $3-5$ & $3-4$ & $3-3$ \\
\hline & & Maths & $3-5$ & $3-4$ & $3-4$ \\
\hline & \multirow[t]{2}{*}{ Sam } & English & $3-4$ & $2-2$ & $2-4$ \\
\hline & & Maths & $3-5$ & $3-4$ & $4-4$ \\
\hline
\end{tabular}

\section{Shared Themes in participants' autobiographies}

The most consistent themes in participants' autobiographies, were how they struggled with the level of independence and self-sufficiency expected from the secondary school and the 
extent to which they were amenable to the influence of their peers. Regarding the former, most participants still sought the more personal and individualised support from teachers that they had experienced at primary school. At primary school they had the same class teacher throughout the day and for the duration of the school year. The teachers knew them well and were able to establish a close relationship with them. At secondary schools, by contrast, subject teachers had contact with well over a hundred students a day and the learning environment was constructed to cater for students who are relatively independent and selfsufficient. Eight of the participants in this study had difficulties coping with this more impersonal setting and sought the person -centred support they had experienced at primary school for a variety of reasons. In the case of Hayley and Chelsea, their need for emotional support was associated with very challenging home circumstances whereas the other six simply did not appear to be ready for the level of independence and self-reliance expected from them at secondary school. As the quotes below from David and Ben illustrate they still sought personal support from teachers, who were forgiving and would praise them whenever they had done well. A level of personal support that mainstream secondary schools rarely provide, and may consider to be inappropriate for the majority of their students.

\section{"I don't think that I have changed much since I finished primary school, I still like teachers} who are nice and help me out whenever I need it". (David)

"I would like to focus more, maybe sit by myself. But with a teacher to help me, and I would like a teacher to tell me when I done well and to get a green card". (Ben)

The other theme that became the focus of interventions was the extent to which students were pre-occupied by the views of their siblings, friends and peers, and their social status amongst their peers. It seemed that the reduction in pastoral support and the increase in autonomy at secondary school made these students more susceptible to becoming 
influenced by their friends and peers, constructively in some cases and very unhelpfully in others. The kind of influence that peers exerted on them varied. Sometimes it was simply a case of becoming easily distracted and chatting when lessons were perceived to be boring. Other times, however, it was important not to lose face in-front of their classmates. In particular, Lenny, Dean and Finley thought that they had a tough-guy reputation to maintain, that required them to act tough by pushing others around, and becoming easily offended by what they perceived to be weaker students. In the case of Dean this need to act tough was enhanced by his father having been in prison, and Lenny was under pressure from his older brothers to "act big" and stand up for himself. The requirement to maintain and project a tough image in front of others, however, was not something that either of them felt at ease with much of the time. In Maths and English, they welcomed the opportunity to sit by themselves and to receive support and attention from their teachers. Indeed, for these adolescent boys there existed side-by-side the desire to be accepted and recognised by their peers as self-sufficient and assertive young men, alongside the continued wish to be treated as vulnerable boys in need of additional time, care and support from their teachers.

\section{Limitation of the study and the intervention}

On the basis of this qualitative study it is not possible to make a definitive connection between the narrative counselling that adolescents received and the progress that the they made in terms of their conduct and educational engagement. The progress that the students made may be attributable to confounding variables, such as students having had the opportunity to talk with a supportive adult regularly and the additional attention they received from teachers and their parents, In this study we also did not obtain an indication of the impact that the intervention may, or may not, have had on participants in the longer term. Measurement of progress made six months or a year later, supported by school data, would have provided further support for the initial findings of the study. 
One critical assumption that is made by narrative therapists is that individuals' perceptions of themselves and their ability to change is closely bound up with the society and cultural in which they live (Madigan, 2019; Payne, 2006). Therefore, to bring about change in how students relate to others in institutions, such as schools, depends not only on their motivation and sense of agency to change themselves and their circumstances but equally importantly on how flexible organizations are in accommodating them. This narrative counselling intervention therefore also relied on support from home, and more importantly their teachers at school.

As external agents the counsellors became increasing aware that the performance orientated culture of the schools, had a critical impact on the implementation of the interventions and their effectiveness. In this case, schools B and C, in particular, were under pressure to improve their students' overall academic performance and in consequence they became increasingly intolerant towards their more challenging students. Teachers had very limited time available to meet with the counsellors or to spend additional time with the students who were misbehaving in their lessons. While the simple reason usually given for a lack of engagement was that no time is available, what this actually meant was that working with these students was not a priority as other, presumably performance related matters, took up most of their time.

The expectation in the organisation that time should not be prioritized for "high maintenance" students also meant that there was very limited communication between senior staff and other teachers, and between teachers and parents regarding students causing concern because of their behaviour in class. In consequence, the request at the start of the project to work together was not passed on to teachers, and requests to see teachers, while the project 
was ongoing, were perceived as problematic and often overlooked. This made liaising with relevant staff, while visiting the school, almost impossible as they were not scheduled to meet with the counsellor.

Finally, in order to try and improve their performance school B and C used their authority and adopted a zero tolerance policy towards "disruptive students" during course of the intervention. The school ethos changed from some attempt to support and keep students to excluding adolescents that they experienced as disruptive and demanding students. In fact, Oscar (who attended school C) was permanently excluded from school very soon after the zero tolerance policy had been put into effect without consulting with or notifying his counsellor. The attitude that these schools had towards this group of students can best be summarised as putting the interests of the school before the interests of "high maintenance" students.

This inverse relationship between the requirement to constantly improve students' academic performance within a highly competitive education system, on the one hand and the quality of support available for disruptive students on the other has also been recognised and commented on in recent publications on school exclusion (Department for Education, 2019; Munn, Lloyd, \& Cullen, 2000). In support of these comments, a recent survey of school leaders on the impact of marketization on the education system in England found that $77 \%$ of those who took part "felt incentivized to prioritize the interest of the school over the interest of particular groups of, usually more vulnerable, children" (Greany \& Higham, 2018, p. 12). When working with schools as a counsellor this attitude towards students not well suited to the institution was visible in teachers' strong reluctance to go beyond superficial and formulaic forms of engagement with this group of students. More personalized engagement would have required more frequent and in-depth conversations with the students to get to know them and their circumstances. Besides time, such activities would also require 
emotional engagement which, as research on emotional labor has demonstrated, may increase levels of stress particularly in performance orientated institutions (Kinman, Wray, \& Strange, 2011). It may therefore also be better for teachers' own well-being to locate the reasons for students' challenging behaviors at school, within the child and his/her family, and the need for mental health expertise that teachers do not possess.

\section{Conclusion and Future Directions}

The method of narrative counselling adolescents described in this paper differs fundamentally from narrative therapy with adults, in that rather than reframing an existing life story it involves creating an autobiography usually for the first time, and that the intervention extends beyond individual work with the young person to relying also on the support of parents and teachers. The purpose of this project was to trial this form of narrative counselling with adolescents who were at risk of exclusion from school, and to identify themes in students' narratives that became the focus on the intervention.

The outcomes from this small scale intervention suggest that school based narrative counselling may produce an improvement in behavioural engagement of adolescent students whose conduct teachers found very challenging and disruptive. What seemed to help students begin to improve was the co-construction of their autobiographies, as it gave them a coherent backstory for their lives at school and a platform for making progress. In addition, the autobiographies contained recurring themes such as their fluctuating relationships with fellow students, their approach to school work, or their changing attitude and relationships with teachers. Any changes in these themes over time then provided insights into possible strategies that the student may apply in the current context to improve their educational engagement. The most common autobiographical themes that the counsellor and the students worked on related to the level of independence and self-reliance that was expected from them 
at secondary school and the extent to which they were influenced negatively in their behaviour at school by their friends and peers.

In addition, the effectiveness of the intervention in part depended on parents and teachers supporting the actions that the student had agreed to take in the counselling sessions. In this respect, the support of relevant teachers was particularly important to maintain a student's progress especially in the long term. Such a reliable level of support from teachers, however, was difficult to obtain in an education system where competition between schools has been left unchecked so that the success and survival of a school, depends on the performance of the majority of their students and not on their ability to improve the life chances of their more vulnerable students.

Looking towards the future, the findings from this intervention suggest that a different form of narrative therapy in which autobiographical narratives are con-constructed between therapists and their clients, usually for the first time, can be particularly effective for adolescents when certain criteria are met. The first and most important of these criteria, is that there needs to be support from significant adults and institutions for the intervention to be successful. Adolescents have less autonomy than adults, especially at school, so that for an intervention to succeed it not only needs the support of significant adults (in this case parents, and one two teachers) but also a positive and genuinely inclusive disposition from the leadership of the school.

As was made clear in the section on the study's limitation there is a need to conduct quantitative research on a larger scale, over an extended period of time, and with different groups of students, so that more reliable findings can be obtained. In addition, such research should collect standardized numerical data not only on the improvements that students have made in their conduct at school and their perceived improved in educational engagement, but 
also in the academic progress that they have made in the subject areas that they have been struggling with the most. Ideally such quantitative research would be conducted in combination with further qualitative forms of inquiry. One way that this could be realized is that narrative solutions interventions were to be conducted by trained staff employed by the school, such as teachers or other staff with experience in and responsibility for vulnerable students and/or students who are displaying challenging behaviours at school. By adopting this integrated approach, the use of narrative counselling could become incorporated into the pastoral support system of the school. We make this suggestion, since this form of narrative counselling is not demanding in terms of understanding psychological theories, or complex in its implementation so that it can be "given away" to teachers and other staff with responsibility for pastoral care in secondary school. By giving schools the opportunity to engage in narrative counselling themselves the scale of the intervention can be increased sufficiently so that its effectiveness can be measured and statistically evaluated. Under these circumstances the assessment of progress made would not only rely on self-report measures but also include measurement of the progress that the students have made academically, and reports from teachers over an extended period of time,

With this mind, we have been conducting interventions alongside training staff at two secondary schools so that they may engage in narrative solution interventions with students, (between the age of 12-14 years) considered to be at risk of exclusion. Here, again the inclusive culture of the two schools vis-à-vis students who come across as difficult and challenging in their behaviour has contributed to the extent to which the training and application have been successful. Besides the nature of the school, the critical conditions for a successful intervention appear to be, the co-creation of a coherent backstory in the early session/s, the identification of recurring themes or patterns of behaviour that are open to revision and can therefore be reframed, the agreement on actions that the student can take on 
a weekly basis, and the communication and elicitation of support from significant parent/s and relevant staff at school. All of this, we suggest, can be provided by staff at school, so long as they are given the time to carry out the interventions and support from senior staff, particularly in highlighting the importance of such work with vulnerable students in their school.

\section{References}

Bohn, A., \& Berntsen, D. (2008). Life story development in childhood: the development of life story abilities and the aquisition of cultural life scripts from late middle childhood to adolescence. Developmental Psychology, 44, 1135 - 1147.

Boyatzis, R. E. (1998). Transforming qualitative information: thematic analysis and code development. Thousand Oaks: Sage.

Braun, V., \& Clarke, V. (2006). Using thematic analysis in psychology. Qualitative Research in Psychology, 3(2), 77-101.

Bruner, J. (1987). Life as narrative. Social Research, 54, 11-32.

Chan, S. M., \& Chan, K. W. (2013). Adolescents' susceptibility to peer pressure: Relations to parentadolescent relationship and adolescents' emotional autonomy from parents. Youth and Society, 45(2), 286-302.

Chester, C., Jones, D. J., Zalot, A., \& Sterrett, E. (2007). Psychological adjustment of African American youth from single mother homes: the relative contribution of parents and peers. Clinical Child and Adolescent Psychology, 36, 356 -366.

Collibee, C., Le Tard, A. J., \& Wargo Aikins, J. (2016). The moderating role of friendship quality on associations between autonomy and adolescent adjustment. Journal Early Adolescence, 36(2), 251-266. 
Conner, J., \& Pope, D. (2013). Not just robo-students: Why full engagement matters and how schools can promote it. Journal of Youth and Adolescence, 42(9), 1426-1442. doi:10.1007/s10964013-9948-y

Cullingford, C., \& Morrison, J. (1997). Peer group pressure within and outside school. British Educational Research Journal, 23(1), 61-80.

Department for Education. (2010). Statistical first release: School, pupils and their characteristics: January 2010. London: Department for Education.

Department for Education. (2015). Statistical first release: Permanent and fixed period exclusions in England: 2013 to 2014: Department for Education.

Department for Education. (2019). Timpson review of school exclusion. London.

Erikson, E. H. (1959). Identity and the life cycle: Selected papers. Psychological Issues, 1, 5-165.

Farouk, S. (2017). My life as a pupil: The autobiographical memories of adolescents excluded from school. Journal of Adolescence, 55, 16-23.

Fivush , R., \& Merrill, N. (2016). An ecological systems approach to family narratives. Memory Studies, 9(3), 305-314.

Gill, K., Quilter-Pinner, H., \& Swift, D. (2017). Making the difference: Breaking the link between school exclusion and social exclusion. London: Institute for Public Policy Research.

Greany, T., \& Higham, R. (2018). Hierarchy, markets and networks: Analysing the 'self-improvement school-led system' agenda in England and the implications for schools. Retrieved from London:

Griffiths, A., Lilles, E., Furlong, M. J., \& Sidhwa, J. (2012). The relationship of adolescent student engagement with troubling and high-risk behavior. In S. L. Christenson, A. L. Reschly, \& C. Wylie (Eds.), Handbook of Research on Student Engagement. London: Springer.

Grysman, A., \& Hudson, J. A. (2010). Abstracting and extracting: Causal coherence and the development of the life story. Memory, 2010(6), 565-580.

Habermas, T., \& de Silveira, C. (2008). The development of global coherence in life narratives across adolescence: Temporal, causal and thematic aspects. Developmental Psychology, 44, 707721.

Hartup, W. W., \& Stevens, N. (1999). Friendship and adaptation across the lifespan. Current directions in psychological science, 8(3), 76-79.

Helsen, M., Vollebergh, W., \& Meeus, W. (2000). Social support from parents and friends and emotional problems in adolescence. Journal of Youth and Adolescence, 29, 319-335.

Kinman, G., Wray, S., \& Strange, C. (2011). Emotional labour, burnout and job satisfaction in UK teachers: the role of workplace social support. Educational Psychology, 31(7), 843-956.

Köber, C., Schmiedek, F., \& Habermas, T. (2015). Characterising lifespan development of three aspects of coherence in life narratives: A cohort-sequential study. Developmental Psychology, 51(2), 260-275.

Madigan, S. (2019). Narrative therapy (2nd ed.): American Psychological Association.

McAdams, D. P. (2003). Identity and the life story. In R. Fivush \& C. A. Haden (Eds.), Autobiographical memory and the construction of a narrative self: Developmental and cultural perspectives (pp. 187-207). London: Lawrence Erlbaum Associates.

Milner, J., \& O'byrne, P. (2002). Brief Counselling: narratives and solutions.

Munn, P., Lloyd, G., \& Cullen, M. A. (2000). Alternatives to Exclusion from School. London: PCP.

Payne, M. (2006). Narrative therapy: An introduction for counsellors (2nd edition ed.). London: Sage.

Steinberg, L., \& Silverberg, S. B. (1986). Vicissitudes of autonomy in early adolescence. Child Development, 57, 841-851.

Symonds, J. (2015). Understanding school transition: What happens to children and how to help them. London: Routledge.

Ungar, M. T. (2001). Constructing narratives of resiliences with high-risk youth. Journal of Systemic Therapies, 20, 58-73. 